\title{
Piyasa Yoğunlaşması ve İhracat İlişkisi: İSO 1000 Firmaları Üzerine Ampirik Bir Uygulama
}

\author{
Ebubekir KARAÇAYIR *
}

\author{
A. Hakan ÇERMIKLII **
}

Geliş Tarihi (Received): 19.04.2021 - Kabul Tarihi (Accepted): 31.08.2021

\section{$\ddot{O} \mathbf{z}$}

Bir ülkenin ihracat performansının belirlenmesinde bir çok teorik yaklaşım mevcuttur. Endüstri yapısının, ihracat performansı üzerindeki etkisi, endüstriyel iktisat teorisine dayanmaktadır. Endüstri iktisadında önemli bir ağırlığa sahip Yapı-Davranış-Performans paradigması, firmaların ihracat performansının, içinde bulundukları endüstri yapısınından etkilendiğini savunmaktadır. Piyasa yoğunlaşması, endüstrilerdeki rekabetin derecesini göstermekte ve endüstrilerin yapısının belirleyicileri arasındadır. Türkiye ekonomisinde en büyük 500 sanayi kuruluşu ve ikinci 500 büyük sanayi kuruluşu birleştirilerek, İSO (İstanbul Sanayi Odası) 1000 firma listesi elde edilebilmektedir. Çalışmanın temel amacı da bu listeden faydalanılarak, endüstri yapısı (piyasa yoğunlaşması, sermaye yoğunluğu ve ihracatçı oranı) değişkenlerinin ihracat yoğunluğu üzerindeki etkisinin araştırılmasıdır. Türkiye ekonomisinde, panel veri tahmin yöntemi kullanılarak, 2016-2019 dönemi y1llık verileri ile endüstri yapısının ihracat yoğunluğu üzerindeki etkisi incelenmiştir. Türk imalat sanayinde faaliyet gösteren 305 firma verisi, çalışma kapsamında oluşturulan ampirik modellerde analiz edilmiştir. Ampirik sonuçlara göre piyasa yoğunlaşması ve endüstri ihracatçı oranı, ihracat yoğunluğunu pozitif yönde ve istatistiki olarak anlamlı olarak etkilemektedir. Sermaye yoğunluğunun ise ihracat yoğunluğu üzerindeki etkisi anlamsız olarak tespit edilmiştir.

Anahtar Kelimeler: Piyasa Yoğunlaşması, İhracat, Rekabet, İSO

\section{The Relationship Between Market Concentration And Export: An Empirical Analysis On ISO 1000 Firms}

\begin{abstract}
There are many theoretical approaches in determining the export performance of a country. The impact of the industrial structure on export performance is based on industrial economics theory. The StructureConduct- Performance paradigm, which has an important place in the industrial economy, argues that the export performance of firms is affected by the industrial structure they are in. Market concentration indicates the degree of competition in the industries and is among the determinants of the structure of the industries. ISO (Istanbul Chamber of Industry) 1000 firm list is formed by combining Turkey's top 500 and second top 500 industrial enterprises list. The main purpose of the study is to investigate the effect of industry structure (market concentration, capital intensity, and exporter orientation) variables on export intensity by making use of this list. This study investigated the impact of industry structure on export intensity with annual data for the period 2016-20019 by the panel data estimation in the Turkish economy. Empirical models created within the scope of the study analyzed 305 firm data operating in the Turkish manufacturing industry. According to the empirical results, market concentration and the export orientation affect the export intensity positively and statistically. The effect of capital intensity on export intensity is found to be insignificant.
\end{abstract}

Key Words: Market Concentration, Export, Competition, ISO

\footnotetext{
" Doktora Öğrencisi, Ankara Hacı Bayram Veli Üniversitesi, Lisansüstü Eğitim Enstitüsü, İktisat Bölümü, ebuturkey@gmail.com

** Prof. Dr., Ankara Hacı Bayram Veli Üniversitesi, İIBF İktisat Bölümü Öğretim Üyesi, hakan.cermikli@hbv.edu.tr
} 


\section{Giriş}

Firmalar düzeyinde yapılan ihracatın toplamı olan ülke ihracatı, ülkenin ekonomik gelişmişliği ve refah seviyesini belirlemede son derece önemlidir. Ülkelerin ihracat performansı, ülke içerisindeki firmaların geliştirdiği ürünlerin küresel piyasalarda ne kadar rekabetçi olduğu ile yakından ilgilidir. Yeni ürün ve üretim tekniklerinin gelişmesi ile faktör donatımının önemi azalmakta ve karşılaştırmalı üstünlükleri temel alan geleneksel dış ticaret teorileri, firmaların uluslararası piyasalarda başarı ve başarısılığını açıklamada yetersiz kalmaktadır. Bu nedenle, yurt içi rekabeti kapsayan mikro seviyede analizlerin yapılması, firmaların uluslararası piyasada başarısını açıklamada son derece önem arz etmektedir.

Yurt içi rekabetin, uluslararası piyasalardaki performansına ilişkin, birbiriyle yarışan iki önemli hipotez mevcuttur: Bu hipotezler: Tyson ve Zysman (1983) ile Jorde ve Teece (1990) çalışmaları tarafindan desteklenen ulusal şampiyon yaklaşımı (national champion approach) ile Micheal Porter (1990) tarafından desteklenen, rekabetçi yaklaşımdır (competitive approach). Ulusal şampiyon hipotezi, yurtiçi rekabetin seviyesi ile ihracat miktarı arasında negatif bir ilişki öngörür iken; rekabetçi yaklaşım ise pozitif bir ilişki öngörmektedir. Bu çalışmanın amacı, hangi hipotezin Türkiye'de imalat sanayi için daha baskın olduğunu tespit etmektedir.

Endüstri iktisadı teorisinde, piyasa yoğunlaşmasının tespiti amacıyla çeşitli ölçüm yöntemleri geliştirilmiştir. Yoğunlaşma Oranı (CR) ve Herfindahl Hirschman Endeksi (HHI) endeksi, teoride ve pratikte çoğunlukla kullanılan iki endekstir. Yoğunlaşma oranı, piyasadaki en yüksek paya sahip $\mathrm{n}$ sayıdaki firmanın toplam piyasa payıdır. $\mathrm{Bu} \mathrm{n}$ sayısı ampirik çalışmalarda sıklıkla $4\left(\mathrm{CR}_{4}\right)$ ve $8\left(\mathrm{CR}_{8}\right)$ olarak tercih edilmektedir. HHI ise bir endüstrideki, bütün firmaların piyasa paylarının karesi olarak tanımlanmaktadır. Literatürde HHI, CR'ye kıyasla, piyasadaki tüm firmaların piyasa paylarını dikkate alması ve piyasa payı yüksek olan firmalara daha fazla önem vermesinden, daha avantajlı olarak gösterilmektedir.

Çalışmanın sonraki bölümlerinde, öncelikle piyasa yoğunlaşması ölçüm yöntemleri açıklanmış, piyasa yoğunlaşması ile ihracat ilişkisine teorik olarak açıklama getirilmiştir. Piyasa yoğunlaşması ile ihracat arasındaki ilişki, İSO 1000 firma listesi kullanılarak 2019 yılı için NACE (Avrupa Topluluğunda Ekonomik Faaliyetlerin İstatistiki Sınıflaması) Rev (Revizyon) 2, 2 haneli endüstri düzeyinde araştırılmıştır. Piyasa yoğunlaşması ile ihracat arasındaki ilişkiyi esas alan çalışmaların ampirik bulguları, literatür taramasında özet tablo olarak sunulmuştur. Çalışmanın ampirik bölümünde ise 2016-2019 dönemi için yıllık veriler 
ile panel veri regresyon yöntemi kullanarak, imalat sanayinde belirlenen 305 firma için piyasa yoğunlaşmasının ihracat üzerindeki etkisi test edilmiştir.

\section{Kavramsal Açıdan Piyasa Yoğunlaşması}

Bir endüstrideki firmaların, piyasa paylarının dağglımının göstergesi niteliğinde olan piyasa yoğunlaşması, endüstrideki firmaların piyasayı kontrol durumu hakkında bilgi sunmaktadır. Endüstrinin, çok sayıda firma tarafından kontrolü durumunda rekabetçi ve yoğunlaşmamış; az sayıda ve eşitsiz dağılıma sahip firmalarca kontrolü durumunda ise rekabetçi olmayan ve yoğunlaşmış piyasa söz konusudur (O'Shaughnessy, 2018, s. 902).

$\mathrm{CR}_{4}$ yoğunlaşma oranı, bir endüstrideki en büyük pay büyüklüğüne sahip 4 girişimin payları toplamının, o endüstrideki toplam pay büyüklüğüne oranıdır. HHI ise endüstrideki bütün firmaların piyasa paylarının karelerinin toplamıdır. HHI endeksi CR'ye kıyasla iki avantaja sahiptir. HHI endeksinde, endüstrideki tüm firmalar hesaplamaya dahil edilmektedir. Ayrıca HHI endeksinde, endüstrideki firmaların piyasa paylarının karesi alındığından, büyük firmalara, küçük firmalara kıyasla daha fazla önem verilmektedir (Ildırar ve Kıral, 2018, s. 98).

Piyasa yoğunlaşmasının ölçümüne yönelik olarak, birçok yaklaşımı temel alan ölçüm yöntemi geliştirilmiştir. Yoğunlaşmanın ölçümünde ise sistematik bir sınıflandırma bulunmamaktadır. Yoğunlaşma yönteminin seçimi, araştırmacının rekabet algısına bağlı olarak değişkenlik gösterebilmektedir. CR ve HHI, teoride ve pratikte çoğunlukla kullanılan iki endeks arasında gösterilmektedir. CR için sınırlı veri yeterli iken; HHI ise sade ve anlaşılır yapıda olması, CR ile HHI'nin, ampirik çalışmalarda sıklıkla tercih edilmesini açıklamaktadır. Ayrıca bu iki endeks, piyasadaki rekabetin ölçülmesinde, ABD başta olmak üzere bir çok ülkede resmi kurumlarca geçerlidir (Bikker ve Haaf, 2002, s. 36).

CR endeksi kapsamında, endüstrideki firma sayıları dikkate alınarak ölçümler yapılmaktadır. Endüstrideki toplam çıktının, o endüstrideki en büyük 4 firma tarafından gerçekleştirildiği varsayan, $\mathrm{CR}_{4}$ endeksi bu kapsamda sıklıkla kullanılmaktadır. $\mathrm{CR}_{4}$ endeksi hesaplandıktan sonra, sayısal değerlerin yorumlanmasında çeşitli referans değerler mevcuttur. TUIKK (2017)'de CR 4 için referans değerleri şu şekilde belirtmiştir. Yoğunlaşma düzeyleri; $\mathrm{CR}_{4}$ $<30$ ise düşük derecede yoğunlaşma, $30 \leq \mathrm{CR}_{4}<50$ ise orta derecede yoğunlaşma, $50 \leq \mathrm{CR} 4$ $<70$ ise yüksek derecede yoğunlaşma, $\mathrm{CR}_{4} \geq 70$ ise çok yüksek derecede yoğunlaşma. Endeks 0'a yaklaşması durumunda endüstri, tam rekabete; 100'e yaklaşmasında ise endüstri, monopole yaklaşmaktadır. 


\section{Piyasa Yoğunlaşması ve İhracat İlişkisi}

Uluslararası ticaret ile piyasa yoğunlaşması arasındaki ilişkinin teorik olarak araştırılması White (1974) çalışmasına dayanmaktadır. Bu çalışmada, yurtiçi piyasa yapısı ile ihracat/ithalat arasındaki ilişinin analiz edilmesi için yararlı bir teorik çerçeve sunulmaktadır. Ayrıca çalışmada piyasa yapısı ile dış ticaret arasındaki ilişkinin önemine değinilmektedir. $\mathrm{Bu}$ çalışma, yurt içi piyasa yapısının ticaret üzerindeki etkisine yönelik çalışmaların, teorik başlangıcı görülmekle birlikte, piyasa yoğunlaşması ile ihracat arasındaki ilişki, oldukça az ampirik çalışmanın konusunu oluşturmaktadır (White, 1974, s. 1013).

Bir ülkenin piyasa yoğunlaşmasının, uluslararası ticaretteki performansını nasıl etkilediğini açıklamak için iki yaklaşım bulunmaktadır: Ulusal şampiyon (national champion) yaklaşımı ve Rekabetçi (compettive) yaklaşım (Hollis, 2003, s. 103). Bu yaklaşımlar, birbiri ile yarışan iki hipotez olarak da değerlendirilmektedir. Ulusal şampiyon yaklaşımı, rekabetçi firmaların iş birliği yapması ve rekabet karşıtı hukuk kurallarının esnetilmesinin, büyük firmaların uluslararası piyasalarda performansını attıracağını savunmaktadır. Rekabetçi yaklaşım ise yurtiçi rekabet ile birleşme karşıtı hukuk kurallarının, firmaların uluslararası piyasalarda başarısı için gerekli olduğunu savunmaktadır (Kim ve Marion, 1997, s. 336). Her iki yaklaşım da ihracat ile rekabet ilişkisini açıklayan hipotezler olarak değerlendirilmektedir (Clougherty ve Zhang, 2009, s. 440).

Ulusal şampiyon yaklaşımının temellendirilmesi ve ayrıntılı olarak incelenmesi için Tyson ve Zysman (1983) ile Jorde ve Teece (1990)'in çalışmalarının incelenmesi gerekmektedir. Tyson ve Zysman (1983) çalışmasında, sanayi politikaları ile rekabetçi sektörlerin oluşabileceğini savunmuştur. II. Dünya savaşı sonrasında, ABD ekonomisi gelişmiş ülkelere kıyasla bazı sektörlerde rekabetçi üstünlüğünü kaybetmiştir. Rekabetçiliğin kaybedilmesinde, tröst politikalarından uzaklaşılması etkili olmuştur. Serbest ticaretin devam etmesi ve kaybedilen rekabet avantajının geri kazanılabilmesi için; ölçek ekonomisinden yararlanılması ve aşırı kısıtlayıcı şirket birleşme kurallarının esnetilmesi gerekmektedir.

Jorde ve Teece (1990)'in çalışması da, Tysman ve Zysmon (1983) çalışmasında olduğu gibi ABD ekonomisinin, Japonya ve Avrupa'daki gelişmiş ekonomilerden geri kalmasını, mevcut izlenen antitröst politikalar ile açıklamaktadır. Yatay ve dikey firma birleşmeleri, başarılı inovasyon için gerekmektedir. Büyük firmalara göre, firmalar arası iş birliğine ihtiyacı olan orta ölçekteki firmalar daha risklidir. Küreselleşme ile taklit üretimi artmakta ve bu nedenle rekabetçi sektörler için, antitröst politikalardan uzaklaşılması gerekmektedir. 
Ulusal şampiyon yaklaşımına göre hükümetler, ölçek ekonomilerinden yararlanacak az sayıda firmada, kaynakları toplulaştırarak, uluslararası rekabetçi endüstrilerin gelişmesine yardımcı olabilirler (Hollis, 2003, s. 103). Yurt içi rekabetteki azalma, firmaların ölçek ekonomilerinden daha çok yararlanmasına olanak tanımakta ve bu şekilde büyük firmalar daha fazla ihracat yapmaktadırlar (Bramati, Gaggero ve Solomon, 2015, s. 2).

Rekabetçi yaklaşıma göre firmalar, rekabet aracılı̆̆ 1 ile büyüyerek ihracat potansiyellerini arttırırlar. Rekabatçi yaklaşımın temelinde ise Porter (1990) çalışması, mevcuttur. Porter (1990) çalışmasında, bir ülkenin rekabet avantajını yakalayabilmesinde dört önemli özellik (faktör koşulları, talep koşulları, ilgili ve desteklenen endüstri, firma stratejisiyapısı ve rekabet) tanımlamaktadır. Bu özellikler içerisindeki yurt içi rekabet, rekabet avantajının yakalanabilmesinde son derece önemlidir. Rekabetteki artış verimlilik ile inovasyonu tetiklemektedir. Firma birleşmeleri ile büyük ortaklıkların gerçekleşmesi, rekabetten uzaklaşılmasına ve rekabet avantajının kaybedilmesine neden olmaktadır.

Porter (1990) kitabında, vaka incelemeleri ile yurtiçi piyasada rekabetten uzaklaşılmasının, nadiren uluslararası rekabetçi avantaj ile sonuçlandığını açıklamaktadır. Ayrıca gelişmiş ülkelerde, birleşme ve ortaklıklara müsamaha gösterilmesini ise eleştirmektedir (Hollis, 2003: 103). Yurtiçi rekabetteki artış, firmaların inovasyona yönelmesinde bask1 oluşturarak, üretim ve verimlilik seviyesini arttırmakta ve böylece firmalar ihracat seviyesini arttırmaktadır (Bramati vd., 2015, s. 2).

Ülkedeki firmaların ihracat performansının en önemli belirleyicisi olarak, ihracat yoğunluğu kabul edilmektedir. Bu durum ihracat performansının belirlenmesinde ihracat yoğunluğunun dikkate alınması gerektiğini doğrulamaktadır (Reis ve Forte, 2014, s. 4). İhracat performansin ampirik olarak belirleyicilerinin teorik temelleri, geleneksel ticaret teorisine dayanan Heckser-Ohlin teoremi ile yeni ticaret ve içsel büyüme teorilerine dayanmaktadır (Liu ve Shu, 2003, s. 46).

Yapı-Davranış-Performans (SCP) paradigması, endüstri iktisadında baskın ve son derece önemlidir. 1950 yılı sonrasında SCP paradigması, endüstri iktisadının gelişmesine katkı sunmuş ve yeni ampirik çalışmaların gerçekleşmesini kolaylaştırmıştır. 1980 yılı ve sonrasında endüstri iktisadında etkili olan Yeni Ampirik Endüstriyel Organizasyon yaklaşımına rağmen; SCP yaklaşımı, sahip olduğu teorik birikimi ile yeni çalışmalar için de önemini korumaktadır (Lee, 2007, s. 17). 
SCP yaklaşımına göre, piyasadaki rekabetin azalması, piyasadaki firmaların piyasa gücünü ve karlılıklarını arttırmasına neden olmaktadır. Firma sayısındaki azalma ile firmaların kendi aralarında iş birliği yapma ihtimalleri de güçlenmektedir (Coşkun vd., 2012, s. 45). SCP paradigması, firmanın ihracat performansının, firmaların içinde bulundukları endüstrinin yapısından ayrı olarak değerlendirilemeyeceğini savunmaktadır ( $\mathrm{Fu}, \mathrm{Wu}$ ve Tang, 2009, s. 4). SCP yaklaşımında, piyasa yapısı ve rekabetin araştırılması için, piyasa yoğunlaşmasının tespiti önerilmektedir. Piyasa yoğunlaşması haricinde sermaye yoğunluğu ve endüstrideki ihracatçı oranı, ihracat performansı üzerinde etkisi araştırılan bazı endüstri yapısı göstergeleri arasindadir.

Sermaye yoğunluğundaki artışın maliyetlerdeki azalma, operasyonel avantajlar ile dış pazarlara girişi kolaylaştırdığı ve böylece ihracat yoğunluğunu da arttırdığı savunulmaktadır. Ancak iş gücü yoğunluğunun yüksek, sermaye yoğunluğunun düşük olduğu endüstrilerde ise ucuz iş gücü avantajı, ihracat yoğunluğunun artmasını sağlamaktadır. Bu nedenle sermaye yoğunluğunun, ihracat yoğunluğu üzerinde etkisi, teorik olarak piyasa yoğunlaşma oranı gibi değişkenlik göstermektedir (Reis ve Forte, 2014, s.7). Endüstrideki ihracatçı oranındaki artışın ise firmaların ihracat yoğunluğunu olumlu etkilemesi beklenmektedir. Çünkü aynı endüstrideki firmalar birbirleri üzerinde etkili olup, özellikle ihracatçı ve başarılı firmalar ihracacatçı olmayan firmalarca takip edilmektedir. Ayrıca dış pazarlar hakkında bilgi sahibi olmuş ve yetenekli iş gücüne sahip bir endüstri, firmaların ihracat maliyetlerini azaltmasını sağlayabilir (Fu vd., 2009, s. 5).

\section{Türk İmalat Sanayisinde Piyasa Yoğunlaşması ve İhracat}

Türkiye ekonomisi imalat sanayinde girişmlerin büyük çoğunluğu KOBİ sınıfında yer almaktadır. TUİK verilerine göre, 2019 yılı itibariyle imalat sanayindeki girişimlerin \%99'u KOBİ iken; \%1'i ise büyük işletmelerdir. Ancak girişim sayısında KOBİ'lerin fazla olmasına rağmen; yapılan ihracatın önemli bir kısmı büyük işletmeler tarafından gerçekleşmektedir. TUİK verilerine göre, 2019 yılı toplam imalat sanayi ihracatının \%64'ü büyük, \%36'sı ise KOBİ işletmeleri tarafından yapılmıştır.

Türkiye ekonomisi sanayi ihracatının en önemli bileşeni imalat sanayi ihracatıdır. İmalat sanayi ihracatındaki değişim, hem sanayi ihracatını hem de toplam ihracat üzerinde belirleyicidir. Tablo 1'de girişim sayıları itibariyle 2016-2019 y1lları arasındaki ihracat değerleri sunulmuştur. Buna göre ilk 1000 firmanın toplam ihracatı, toplam sanayi ihracatın (2016-2019 yıllları için) \%75'ini oluşturmaktadır. 
Tablo 1. Sanayi Girişimlerinde İhracatta Yoğunlaşma (Bin \$)

\begin{tabular}{|l|c|c|c|c|}
\hline Girişim Sayısı & $\mathbf{2 0 1 6}$ & $\mathbf{2 0 1 7}$ & $\mathbf{2 0 1 8}$ & $\mathbf{2 0 1 9}$ \\
\hline İlk 5 girişim & $14,032,576$ & $18,626,658$ & $17,833,102$ & $18,292,477$ \\
\hline İlk 10 girişim & $19,534,963$ & $24,435,238$ & $24,843,138$ & $24,857,063$ \\
\hline İlk 20 girişim & $24,336,475$ & $29,709,548$ & $30,681,043$ & $31,074,441$ \\
\hline İlk 50 girişim & $30,495,934$ & $35,899,272$ & $37,771,965$ & $38,272,237$ \\
\hline İlk 100 girişim & $36,391,728$ & $42,104,481$ & $44,473,891$ & $45,396,417$ \\
\hline İlk 500 girişim & $52,646,254$ & $60,246,830$ & $64,755,907$ & $66,502,053$ \\
\hline İlk 1 000 girişim & $60,403,682$ & $68,615,444$ & $74,160,105$ & $76,366,271$ \\
\hline Tüm girişimiler & $79,719,843$ & $90,253,659$ & $98,254,545$ & $102,640,100$ \\
\hline
\end{tabular}

Kaynak: TUIK

Şekil 1'de 2019 yılı itibariyle, İSO ilk 1000 sanayi kuruluşu verisi kullanılarak, endüstriler düzeyinde piyasa yoğunlaşması ile ihracatın durumu gösterilmiştir. Şekildeki balonlar içerisindeki rakamlar, endüstri kodlarını göstermekte olup, 29 ve 24 numaralı endüstriler diğer endüstrilerden belirgin şekilde ayrıştığından bu endüstriler şekilden çıkarılmış; ama yapılan analiz çalışmasından çıkarılmamıştır. İncelenen endüstriler NACE Rev 2. 2 haneli düzeyde olup, imalat sanayini kapsamaktadır. Dikey eksende piyasa yoğunlaşma HHI endeksi, yatay eksende ise ihracat değeri gösterilmiştir. Her iki gösterge de imalat sanayindeki firmaların verisi kullanılarak endüstri düzeyinde hesaplanmıştır.

Şekil 1. 2019 Y1lı Piyasa Yoğunlaşması ve İhracat

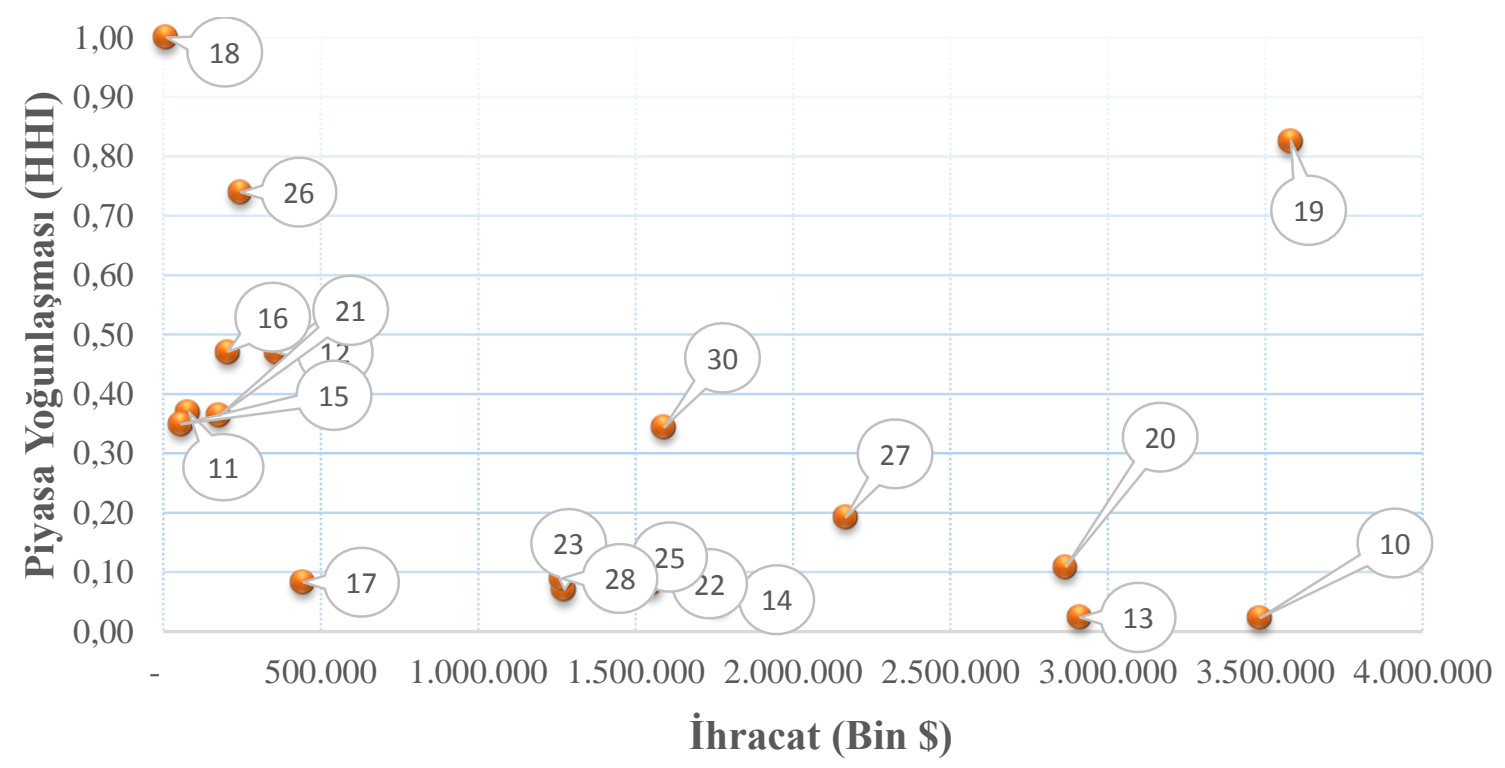

Kaynak: İSO verileri kullanılarak yazarlar tarafından hesaplanmıştır. 
Dikey eksende gösterilen piyasa yoğunlaşmasında, yukarı doğru gidildikçe piyasada yoğunlaşma düzeyi artar iken; rekabet düzeyi ise azalmaktadır. HHI değeri, U.S. Department of Justice and the Federal Trade Commission raporunda (2010) belirtildiği gibi 0.25 'in üzerinde olduğu durumda, yoğunlaşmış; 0.25 'in altında ve 0.15 'ten büyük olduğu durumda kısmen yoğunlaşmış; 0.15 'ten küçük ise yoğunlaşmamış piyasa söz konusudur. Bu kritik değerler dikkate alınarak, imalat sanayi için belirlenen 21 endüstri için Tablo 2 hazırlanmıştır. Endüstri düzeyinde toplam imalat sanayi ihracatı 56 milyar dolar civarında iken; bu tutarın 8 milyarı yoğunlaşmış ve kısmen yoğunlaşmış; 48 milyarı ise yoğunlaşmamış endüstriler tarafindan gerçekleşmiştir. Yoğunlaşmış ve kısmen yoğunlaşmış endüstrilerin ihracatı, yoğunlaşmamış endüstrilerin ihracatına göre çok daha az tutarda gerçekleşmiştir.

Tablo 2. Endüstrilerin Piyasa Yoğunlaşma Düzeyi

\begin{tabular}{|c|c|c|}
\hline Yoğunlaşmış & Yoğunlaşmamış & Kısmen Yoğunlaşmış \\
\hline 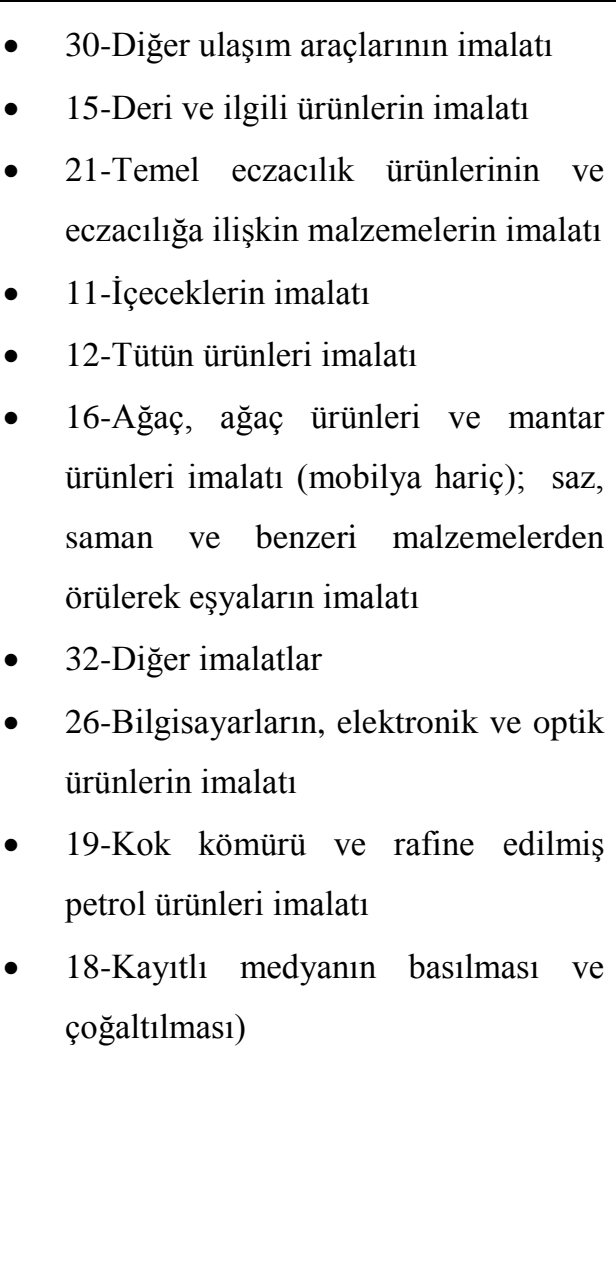 & 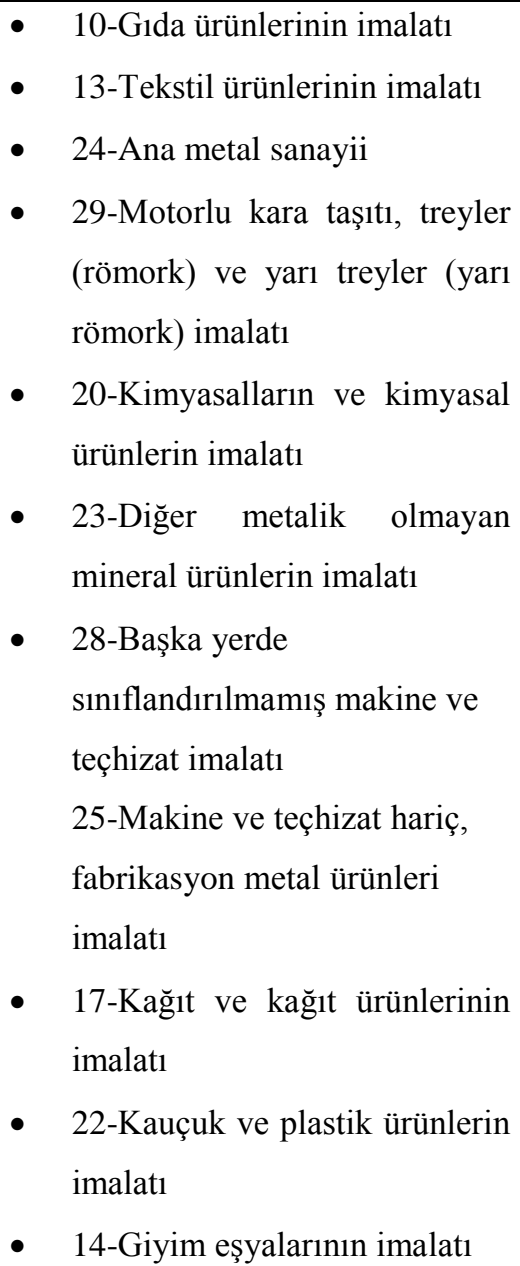 & $\begin{array}{ll}\text { - } & \text { 31-Mobilya imalatı } \\
\text { - } & \text { 27-Elektrikli teçhizat } \\
& \text { imalatı }\end{array}$ \\
\hline
\end{tabular}




\section{Ampirik Literatür}

Piyasa yoğunlaşmasının, ihracat üzerindeki etkisini ölçen çalışmaların sonuçları, literatür taraması kapsamında Tablo 3'de sunulmuştur. Bu tablo, kronolojik sıralama esaslı olarak çalışmaların endüstri, ülke, yıl ve uygulama yöntemlerinin özeti şeklinde hazırlanmıştır. Çalışmalar genel olarak daha çok endüstri yapısı ile diş ticaret arasındaki ilişkiyi araştırmakta olup, piyasa yoğunlaşması ile ihracat arasındaki bulguların raporlanmasına özen gösterilmiştir. Konu ile ilgili uluslararası literatürde farklı ülke ve endüstri uygulamalarını kapsayan çalışmalar bulunmakta iken, Türkiye ekonomisi için yalnızca, Şahin (2008) çalışmasına ulaşılmıştır. Türkiye ekonomisinde bu alanda yapılan çalışmaların, daha çok dış ticaretin piyasa yoğunlaşması veya karlılık gibi piyasa yapısı ve performansı üzerindeki etkisini araştırdığı tespit edilmiştir. Yapılan bu çalışma ise piyasa yapısının, ihracat üzerindeki etkisini araştırdığından, ilgili çalışmalar literatür taraması kapsamı dışında bırakılmıştır.

Tablo 3. Ampirik Literatür Taraması

\begin{tabular}{|c|c|c|c|c|c|c|}
\hline Yazarlar & Yil & Ülke & Dönem & Endüstri & Yöntem & Sonuç \\
\hline $\begin{array}{l}\text { Pagoulatos } \\
\text { ve Sorensen }\end{array}$ & 1976 & Amerika & 1967 & $\begin{array}{l}\text { İmalat Sanayi } \\
\text { (88 endüstri) }\end{array}$ & $\begin{array}{l}\text { Çoklu } \\
\text { Regresyon } \\
\text { Denklemi }\end{array}$ & $\begin{array}{l}\mathrm{CR}_{4} \text { endeksi ile } \\
\text { ihracat arasında } \\
\text { pozitif ilişki vardır }\end{array}$ \\
\hline Glajser vd. & 1980 & Belçika & 1970 & $\begin{array}{l}\text { 14 Endüstri } \\
\text { (970 firma) }\end{array}$ & $\begin{array}{l}\text { Regresyon } \\
\text { analizi }\end{array}$ & $\begin{array}{l}\text { HHI indeksi ile } \\
\text { ihracat arasında } \\
\text { negatif ilişki vardır }\end{array}$ \\
\hline $\begin{array}{l}\text { Koo ve } \\
\text { Martin }\end{array}$ & 1984 & Amerika & 1983 & 237 endüstri & $\begin{array}{l}\text { Regresyon } \\
\text { analizi }\end{array}$ & $\begin{array}{l}\text { Piyasa } \\
\text { yoğunlaşmasının } \\
\text { ihracatı arttırıcı ve } \\
\text { azaltıcı durumları } \\
\text { vardır. } \\
\end{array}$ \\
\hline $\begin{array}{l}\text { Henderson } \\
\text { ve Frank }\end{array}$ & 1990 & Amerika & 1982 & \begin{tabular}{|l|} 
G1da İmalat \\
Sanayi (42 \\
Endüstri) \\
\end{tabular} & $\begin{array}{l}\text { Çoklu } \\
\text { Regresyon } \\
\text { Denklemi } \\
\end{array}$ & $\begin{array}{l}\mathrm{CR}_{4} \text { endeksi, ihracat1 } \\
\text { negatif yönde } \\
\text { etkilemektedir }\end{array}$ \\
\hline El-Osta vd. & 1996 & Amerika & 1982 & $\begin{array}{l}\text { İmalat Sanayi } \\
\text { (248 Endüstri) }\end{array}$ & $\begin{array}{l}\text { Eş zamanl1 } \\
\text { Denklem } \\
\text { Analizi }\end{array}$ & $\begin{array}{l}\text { Piyasa } \\
\text { yoğunlaşmasının } \\
\text { ihracatı azaltıcı etkisi } \\
\text { vardır. }\end{array}$ \\
\hline $\begin{array}{l}\text { Kim ve } \\
\text { Marion }\end{array}$ & 1997 & Amerika & $1967-1987$ & \begin{tabular}{|l|} 
G1da İmalat \\
Sanayi (32 \\
Endüstri) \\
\end{tabular} & $\begin{array}{l}\text { Siradan En } \\
\text { Küçük Kareler } \\
\text { Yöntemi }\end{array}$ & $\begin{array}{l}\text { Piyasa yoğunlaşması, } \\
\text { net ihracatı negatif } \\
\text { olarak etkilemektedir }\end{array}$ \\
\hline Zhao ve Zou & 2002 & Çin & 1990 & \begin{tabular}{|l} 
İmalat Sanayi \\
(37 endüstri, \\
1049 firma)
\end{tabular} & \begin{tabular}{|l|} 
Çoklu \\
Regresyon \\
Denklemi
\end{tabular} & $\begin{array}{l}\text { Piyasa yoğunlaşması, } \\
\text { ihracatı negatif olarak } \\
\text { etkilemektedir }\end{array}$ \\
\hline Hollis & 2003 & 7 Ülke & 1985 & $\begin{array}{l}\text { İmalat Sanayi } \\
\text { (82 Endüstri) }\end{array}$ & $\begin{array}{l}\text { Sabit ve } \\
\text { Rassal Etkili } \\
\text { Panel veri }\end{array}$ & $\begin{array}{l}\text { Piyasa yoğunlaşması, } \\
\text { net ihracatı negatif } \\
\text { olarak etkilemektedir }\end{array}$ \\
\hline
\end{tabular}




\begin{tabular}{|c|c|c|c|c|c|c|}
\hline & & & & & $\begin{array}{l}\text { Regresyon } \\
\text { Modeli }\end{array}$ & \\
\hline Cortes & 2006 & Japonya & 1992-2000 & \begin{tabular}{|l|} 
İmalat Sanayi \\
(56 Sektör)
\end{tabular} & $\begin{array}{l}\text { İmalat Sanayi } \\
\text { (56 Sektör) }\end{array}$ & $\begin{array}{l}\mathrm{CR}_{4} \text {, pozitif yönde } \\
\text { ihracatı } \\
\text { etkilemektedir. }\end{array}$ \\
\hline Şahin & 2008 & Türkiye & $1980-2001$ & $\begin{array}{l}\text { İmalat Sanayi } \\
\text { (74 } \text { Endüstri) }\end{array}$ & $\begin{array}{l}\text { Sabit Etkiler } \\
\text { Panel Veri }\end{array}$ & $\begin{array}{l}\text { Piyasa yoğunlaşması } \\
\text { ile diş ticaret arasında } \\
\text { anlamlı bir ilişki yok }\end{array}$ \\
\hline $\begin{array}{l}\text { Cloughherty } \\
\text { ve Zhang }\end{array}$ & 2009 & 19 ülke & $1987-1992$ & Havacılık & $\begin{array}{l}\text { Dinamik Panel } \\
\text { Veri }\end{array}$ & $\begin{array}{l}\text { Ulusal Şampiyon } \\
\text { yaklaşımını destekler } \\
\text { sonuçlara ulaş1lmıştır. }\end{array}$ \\
\hline Güner vd. & 2010 & $\begin{array}{l}3 \text { ülke } \\
\text { firmaları }\end{array}$ & $2001-2005$ & 1695 firma & $\begin{array}{l}\text { Çoklu } \\
\text { Regresyon } \\
\text { Denklemi }\end{array}$ & $\begin{array}{l}\text { Piyasa yoğunlaşması, } \\
\text { ihracatı pozitif olarak } \\
\text { etkilemektedir }\end{array}$ \\
\hline Bramati vd. & 2015 & Belçika & $2005-2008$ & $\begin{array}{l}\text { Tarım ve su } \\
\text { ürünleri } \\
\text { haricinde } \\
\text { bütün } \\
\text { endüstriler }\end{array}$ & $\begin{array}{l}\text { Kismi Logit } \\
\text { Regresyon }\end{array}$ & $\begin{array}{l}\text { Rekabetçi yaklaşımı } \\
\text { destekler sonuçlara } \\
\text { ulaşılmıştır. }\end{array}$ \\
\hline Reis ve Forte & 2016 & Portekiz & $2010-2013$ & \begin{tabular}{|l|} 
İmalat Sanayi \\
Firmaları
\end{tabular} & $\begin{array}{l}\text { Panel veri } \\
\text { Sabit Etkiler } \\
\text { Modeli } \\
\end{array}$ & $\begin{array}{l}\text { Piyasa yoğunlaşması, } \\
\text { ihracatı pozitif olarak } \\
\text { etkilemektedir }\end{array}$ \\
\hline
\end{tabular}

\section{Veri ve Analiz Sonuçları}

Çalışmanın bu bölümünde 2016-2019 döneminde yıllık veriler kullanılarak, Türkiye ekonomisi imalat sanayisinde endüstri yapısını gösteren değişkenlerin, firmaların ihracat performansı üzerindeki etkisi test edilmiştir. İSO 1000 firmalarının oluşturduğu veri seti, NACE Rev.2, 2 haneli endüstri düzeyinde incelenmiştir. Öncelikle 2016-2019 yılları arasındaki tüm İSO 1000 listesindeki firmalar üzerinde, veri temizleme işlemi yapılmıştır. Firma ismi ve verisi mevcut olmayan veriler temizlenmiş, imalat sanayinde faaliyet gösteren firma verilerine ulaşılmıştır. 2019 yılından başlayarak geçmişe yönelik 4 yıllık sürekli veriye sahip, 305 firma belirlenmiştir. Belirlenen 305 firma dikkate alınarak, endüstri bazlı firma sayısı Ek Tablo: 1 listesinde sunulmuştur. Bu firmalar için endüstri yapısını temsil eden piyasa yoğunlaşma oranı, sermaye yoğunluğu ve endüstrideki ihracatçı oranı değişkenleri hesaplanmıştır. İhracat yoğunluğunu hesaplamak için ise belirlenen 305 firma arasından, ihracatçı konumda olan 248 firma verisi kullanılmıştır. NACE Rev.2, 2 haneli 23 endüstrideki firma verileri kullanılarak, panel veri regresyon yöntemi ile belirlenen modeller test edilmiştir. Çalışmada, Stata 13 paket programından elde edilen sonuçlar raporlanmıştır. 
Tablo 4. Değişkenlerin Açıklanması

\begin{tabular}{|l|l|l|}
\hline Kısaltma & Değişken İsmi & Açıklama \\
\hline EXP & İhracat yoğunluğu & İhracatçı firmaların ihracat değerlerinin net satışlarına oranı \\
\hline CR $_{4}$ & $\begin{array}{l}\text { 4 Firma Yoğunlaşma } \\
\text { Oranı }\end{array}$ & Endüstri düzeyinde hesaplanan 4 firma yoğunlaşma oranı \\
\hline HHI & $\begin{array}{l}\text { Herfindahl Hirschman } \\
\text { endeksi }\end{array}$ & $\begin{array}{l}\text { Endüstri düzeyinde hesaplanan Herfindahl Hirschman } \\
\text { endeksi }\end{array}$ \\
\hline CI & Sermaye yoğunluğu & Endüstri aktif toplamının net satış toplamına oranı \\
\hline EXPIS & İhracatçı oranı & $\begin{array}{l}\text { Endüstri içindeki toplam ihracatçı firma sayısının, toplam } \\
\text { firma sayısına oranı }\end{array}$ \\
\hline REX & Reel döviz kuru endeksi & Yi-ÜFE Bazlı Reel Efektif Döviz Kuru (2003=100) \\
\hline
\end{tabular}

Çalışmada kullanılan değişken ve açıklamaları Tablo 4'te sunulmuş olup, tüm değişkenler modelde logaritmik düzeyde ele alınmıştır. Reel döviz kuru endeksi TCMB EVDS'den indirilmiş olup, modelde kullanılan diğer tüm değişkenler İSO 1000 listesindeki veriler kullanılarak hesaplanmıştır. Değişkenlerin seçiminde teorik ve literatür çalışmaları dikkate alınmış olup; endüstri yoğunlaşmasının firmaların ihracat performansı üzerindeki etkisinin ölçülmesi, çalışmanın temel amacını oluşturmaktadır. Endüstri yoğunlaşması haricinde sermaye yoğunluğu, ihracatçı oranı ve reel döviz kuru endeksi, endüstri yapısını gösteren değişkenler olarak tanımlanmakta olup bu değişkenlerin de ihracat yoğunluğu üzerindeki etkisi test edilmiştir.

Tablo 5. Değişkenlerin Tanımlayıcı İstatistikleri

\begin{tabular}{|l|c|c|c|c|c|}
\hline Değişkenler & $\begin{array}{l}\text { Gözlem } \\
\text { Sayısı }\end{array}$ & Ortalama & $\begin{array}{l}\text { Standart } \\
\text { Sapma }\end{array}$ & $\begin{array}{l}\text { Minimum } \\
\text { Değer }\end{array}$ & $\begin{array}{l}\text { Maksimum } \\
\text { Değer }\end{array}$ \\
\hline EXP & 992 & 0.32 & 0.25 & 0.00 & 1.03 \\
\hline CR4 & 992 & 0.54 & 0.26 & 0.22 & 1.00 \\
\hline HHI & 992 & 0.15 & 0.17 & 0.02 & 1.00 \\
\hline CI & 992 & 1.09 & 0.51 & 0.39 & 4.97 \\
\hline EXPIS & 992 & 0.92 & 0.11 & 0.00 & 0.98 \\
\hline REX & 992 & 86.6 & 6.72 & 79.7 & 96.9 \\
\hline
\end{tabular}

Çalışmada kullanılan değişkenlerin tanımlayıcı istatistikleri Tablo 5'te sunulmuştur. İhracat yoğunluğu 4 yıllık ortalama değeri 0.32 iken, ortalamanın en az olduğu endüstri 18Kayıtlı medyanın basılması ve çoğaltılması (0.06); en fazla olduğu ise 32- Diğer imalatlar 
(0.81) endüstrisidir. $\mathrm{CR}_{4}$ ortalama değeri 0.54 iken, ortalamanın en az olduğu endüstri 13Tekstil ürünlerinin imalatı (0.23); en fazla olduğu ise 11-12-16-18-19-21-26-30-31-32 (1.00) endüstrileridir. HHI ortalama değeri 0.15 iken, ortalamanın en az olduğu endüstri 13- Tekstil ürünlerinin imalatı (0.03); en fazla olduğu ise 12- Tütün ürünleri imalatı ve 18- Kayıtlı medyanın basılması ve çoğaltılması (1.00) endüstrileridir. Sermaye yoğunluğu ortalama değeri 1.09 iken, ortalamanın en az olduğu endüstri 19- Kok kömürü ve rafine edilmiş petrol ürünleri imalatı (0.53); en fazla olduğu ise 11- İçeceklerin imalatı (4.29) endüstrisidir. İhracatçı oranı ortalama değeri 0.92 iken, ortalamanın en az olduğu endüstri 12- Tütün ürünleri imalatı (0.00); en fazla olduğu ise 10- Gıda ürünlerinin imalatı (0.98) endüstrisidir.

Tablo 6. Çapraz Korelasyon Test Sonuçları

\begin{tabular}{|l|c|c|c|c|c|c|}
\hline & INEXP & INHHI & LNCR $_{4}$ & INCI & INEXPIS & INREX \\
\hline LNEXP & 1.00 & & & & & \\
\hline LNHHI & 0.11 & 1.00 & & & & \\
\hline INCR 4 & 0.12 & 0.97 & 1.00 & & & \\
\hline LNCI & -0.19 & -0.18 & -0.17 & 1.00 & & \\
\hline LNEXPIS & 0.06 & -0.64 & -0.58 & -0.27 & 1.00 & \\
\hline LNREX & -0.08 & 0.00 & 0.00 & 0.11 & 0.00 & 1.00 \\
\hline
\end{tabular}

Çalışmada kullanılan değişkenler için, model öncesinde korelasyon testi yapılmış olup, sonuçlar Tablo 6'da sunulmuştur. Değişkenlerin çapraz korelasyon test sonuçlarına göre yoğunlaşmayı gösteren $\mathrm{CR}_{4}$ ve $\mathrm{HHI}$ değişkenleri ile ihracat yoğunluğu değişkeni arasında pozitif korelasyon katsayılarına ulaşılmıştır. İhracat yoğunluğu değişkenin, $\mathrm{HHI}$ ve $\mathrm{CR}_{4}$ değişkenleriyle korelasyon katsayıları sırasıyla ile 0.11 ile 0.12 'dir. Endüstri yoğunlaşmasını temsilen $\mathrm{CR}_{4}$ ve $\mathrm{HHI}$ değişkenleri arasında, beklendiği gibi çok yüksek pozitif korelasyon (0.97) katsayısına ulaşılmıştır.

$$
\begin{aligned}
& \ln E X P_{j i t}=\beta_{0}+\beta_{1} \ln C R 4_{i t}+\beta_{2} \ln C I_{i t}+\beta_{3} \ln E X P I S_{i t}+\beta_{4} \ln R E X_{i t}+y d u m m i e s+\varepsilon_{i t} \\
& \ln E X P_{j i t}=\beta_{0}+\beta_{1} H H I_{i t}+\beta_{2} \operatorname{lnCI}_{i t}+\beta_{3} \ln E X P I S_{i t}+\beta_{4} \ln R E X_{i t}+y d u m m i e s+\mathrm{U}_{i t}
\end{aligned}
$$

Endüstri yoğunlaşması ile diğer endüstri değişkenlerinin, ihracat yoğunluğu üzerindeki etkisini test etmek amacıyla (1) ve (2) denklemlerinde belirtilen 2 farklı model kullanılmıştır.

\footnotetext{
${ }^{1}$ Endüstri kodlarına karşılık gelen tanımlamalar Ek 1'de sunulmuştur.
} 
$\mathrm{Bu}$ denklemlerde $\mathrm{t}$ zamanı, i endüstriyi, $\mathrm{j}$ ise firmayı temsil etmektedir. In değişkenlerin logaritmalarını, $\varepsilon$ ve $U$ ise hata terimlerini ifade etmektedir.

Modellerdeki ydummies değişkeni y1l kukla değişkeni olarak belirlenmiştir. 2018 ve 2019 yılları, incelen yıllar içerisinde İSO 1000 listesindeki firmaların en yüksek tutarda ihracata ulaştığı yıllardır. Ayrıca 2019 yılında İSO 1000 firmaların ihracatı, TUİK ile uyum sağlanması amacıyla Genel Ticaret Sistemi'ne (GTS) göre hesaplanmıştır (ISSO, 2020, s. 18). Bu nedenle bu yıllarda gerçekleşen düzenlemelerin etkileri düşünülerek, 2018 ve 2019 yılları içim kukla değişken kullanılmıştır.

Kullanılan modellerin ilkinde, 4 firma yoğunlaşma oranın, ikinci modelde HHI endeksinin ihracat yoğunluğu üzerindeki etkisi araştırılmıştır. Endüstri yoğunlaşmasının ve sermaye yoğunluğunun ihracat üzerindeki teorik olarak beklenen etkisi pozitif ve negatif yönde değişmektedir. İhracatçı oranının, ihracat yoğunluğunu pozitif yönde; reel döviz kuru endeksinin ise ihracat yoğunluğunu negatif yönde etkilemesi teorik olarak beklenmektedir.

Tablo 7. Hausman Test Sonuçları

\begin{tabular}{|l|c|c|}
\hline Modeller & Ki-Kare Değeri & p-Değeri \\
\hline Model 1 & 3.53 & 0.73 \\
\hline Model 2 & 9.27 & 0.15 \\
\hline
\end{tabular}

Hausman testi, sabit etkili ve rassal etkili modeller arasında karar vermede kullanılan bir test olup, kurulan iki model için yapılan test sonuçları Tablo 7'de sunulmuştur. Hausman testinde açıklayıcı değişkenler ve birim etkisi arasında korelasyon olmadığını öngören boş hipotez, alternatif hipoteze karşı test edilmiştir. Boş hipotezin reddedilmediği durumda rassal etkili; reddedildiği durumda ise sabit etkili model sonuçları desteklenmektedir. Hausman test sonuçlarına göre her iki model için boş hipotezin reddedilmediği için, rassal etkili modeller desteklenmektedir.

Tablo 8. Değişen Varyans ve Otokorelasyon Test Sonuçları

\begin{tabular}{|l|l|ll|l|}
\hline & Modeller & Değişen Varyans & Otokorelasyon Testi \\
\hline Sabit Etkiler & Model 1 & $\begin{array}{l}\text { Değiştirilmiş Wald testi } \\
(0.00)\end{array}$ & Wooldridge testi (0.27) \\
\cline { 2 - 5 } & Model 2 & $\begin{array}{l}\text { Değiştirilmiş } \\
(0.00)\end{array}$ & Wald testi & Wooldridge testi (0.28) \\
\hline
\end{tabular}




\begin{tabular}{|l|l|l|l|}
\hline Rassal Etkiler & Model 1 & $\begin{array}{l}\text { Levene, Brown ve Forsythe } \\
\text { Testi }(0.00)\end{array}$ & LM Testi (0.00) \\
\cline { 2 - 4 } & Model 2 & $\begin{array}{l}\text { Levene, Brown ve Forsythe } \\
\text { Testi }(0.00)\end{array}$ & LM Testi (0.00) \\
\hline
\end{tabular}

Çalışma kapsamında sabit etkiler ve rassal etkiler ile tahmin edilen modellerin otokorelasyon ve değişen varyans testi sonuçları Tablo 8'de raporlanmıştır. Model için kullanılan test istatistiği bilgisi ve testin geçerliliğine karar vermede kullanılan p-değerleri, bu tabloda gösterilmiştir. Sabit etkiler modelinde, değişen varyans için Değiştirilmiş Walt; otokorelasyon için ise Wooldridge testleri kullanılmıştır. Test sonuçlarına göre, sabit etkiler için oluşturulan iki farklı modelde değişen varysans sorunu mevcut iken; otokorelasyon sorunu gözlemlenmemiştir. Rassal etkiler için ise değişen varyans için Levene, Brown ve Forsythe; otokorelasyon için ise LM testleri kullanılmıştır. Test sonuçlarına göre rassal etkiler için oluşturulan iki farklı modelde de değişen varyans ve otokorelasyon sorunu gözlemlenmiştir.

Tablo 9. Rassal Etkiler Modeli Panel Veri Regresyon Sonuçları

\begin{tabular}{|c|c|c|c|c|c|c|c|}
\hline $\begin{array}{l}\text { Bağımlı } \\
\text { Değişken, } \\
\text { INEXP } \\
\end{array}$ & Değişkenler & Katsayı & $\begin{array}{l}\text { Standart } \\
\text { Hata }\end{array}$ & $\begin{array}{l}\text { z- } \\
\text { istatist } \\
\text { iği } \\
\end{array}$ & p-değeri & $\begin{array}{l}\mathbf{R}^{2} \\
\text { (Within) }\end{array}$ & $\begin{array}{l}\text { Wald } \\
\text { chi2 (6) }\end{array}$ \\
\hline \multirow{7}{*}{ Model 1} & $\mathrm{INCR}_{4}$ & 0.692 & 0.195 & 3.55 & $0.000 * * *$ & \multirow{7}{*}{0.1120} & \multirow{7}{*}{105.75} \\
\hline & INCI & -0.214 & 0.223 & -0.96 & 0.338 & & \\
\hline & LNEXPIS & 2.918 & 1.108 & 2.63 & $0.008 * * *$ & & \\
\hline & LNREX & .0565 & 0522 & 1.08 & 0.279 & & \\
\hline & D1 & 0.310 & 0.075 & 4.11 & $0.000 * * *$ & & \\
\hline & D2 & 0.3918 & 0.063 & 6.19 & $0.000 * * *$ & & \\
\hline & C & -3.614 & 2.390 & -1.51 & 0.130 & & \\
\hline \multirow{7}{*}{ Model 2} & LNHHI & 0.437 & 0.121 & 3.61 & $0.000^{* * *}$ & \multirow{7}{*}{0.1160} & \multirow{7}{*}{111.94} \\
\hline & INCI & -0.149 & 0.238 & -063 & -0.617 & & \\
\hline & LNEXPIS & 3.490 & 1.128 & 3.09 & $0.002 * * *$ & & \\
\hline & LNREX & 0.554 & 0.526 & 1.05 & 0.292 & & \\
\hline & D1 & 0.311 & 0.075 & 4.11 & $0.000^{* * * *}$ & & \\
\hline & D2 & 0.386 & 0.063 & 6.07 & $0.000 * * *$ & & \\
\hline & C & -3.004 & 2.458 & -1.22 & 0.222 & & \\
\hline
\end{tabular}


Hausman test sonuçlarına göre Model 1 ve 2 için rassal etkiler panel veri tahmincisi desteklenmekte olup, rassal etkiler modellerinin sınanmasında değişen varyans ve otokorelasyon sorunları ile karşılaşılmıştır. Bu nedenle rassal etkili modellerin tahmini için Arellano, Froot ve Rogers tahmincisi kullanılmış olup; elde edilen sonuçlar Tablo 9'da raporlanmıştır. Elden edilen ampirik bulgular incelendiğinde Model 1 için $\mathrm{CR}_{4}$ değişkeni, ihracat yoğunluğunu \%1 düzeyinde anlamlı ve pozitif yönde etkilemektedir. İstatistiki olarak, piyasa yoğunlaşma oranındaki \%1'lik bir artış, ihracat yoğunluğunun ortalama olarak \%0.7 düzeyinde artmasına sebep olmaktadır. Model 2 için ise HHI değişkeni, ihracat yoğunluğunu \%1 düzeyinde anlamlı ve pozitif yönde etkilemektedir. İstatistiki olarak piyasa yoğunlaşma oranındaki \%1'lik bir artış, ihracat yoğunluğunun ortalama olarak \%0.4 düzeyinde artmasına sebep olmaktadir.

Model 1 ve 2 sonuçları, piyasa yoğunlaşma oranı haricindeki diğer değişkenler bakımından birlikte değerlendirildiğinde: endüstri ihracatçı oranı ile yıl kukla değişkenleri olarak seçilen D1 (2018) ve D2 (2019), ihracat oranını istatistiki olarak anlamlı ve pozitif yönde etkilemektedir. Modellerde sermaye oranı, reel döviz kuru endeksi ve sabit terimin etkisi ise anlamsız olarak tespit edilmiştir.

\section{Sonuçlar}

İSO 1000 listesi kullanılarak, endüstri yapısının ihracat yoğunluğu üzerindeki etkisi, 2016-2019 y1lları için, 305 imalatçı firma verisi kullanılarak, panel veri yöntemiyle test edilmiştir. NACE Rev.2, 2 haneli 23 endüstri düzeyinde piyasa yoğunlaşma oranı, sermaye yoğunluğu ile endüstri ihracatçı oranları hesaplanıştır. Çalışma kapsamında bağımlı değişken olarak belirlenen ihracat yoğunluğu ise listedeki ihracatçı olan firma verileri kullanılarak hesaplanmıştır. Çalışmanın temel amacı piyasa yoğunlaşmasının, ihracat yoğunluğu üzerindeki etkisini test etmek olup; modellerde bağımsız değişken olarak belirlenen sermaye yoğunluğu, ihracatçı oranı ile reel döviz kuru endeksinin de ihracat yoğunluğu üzerindeki etkisi araştırılmıştır.

Piyasa yoğunlaşma ölçütü olarak $\mathrm{CR}_{4}$ ve $\mathrm{HHI}$ endeksleri çalışma kapsamında hesaplanmış olup, bu iki değişkenlerden her biri endüstri yoğunlaşma ölçütü olarak, iki farklı modelde bağımsız değişken olarak seçilmiştir. Arellon, Froot ve Rogers rassal etkiler panel veri tahmincisi, seçilen modeller için en uygun tahminci olarak belirlenmiş olup; piyasa yoğunlaşmasının, ihracat yoğunluğu üzerinde pozitif ve anlamlı etkisine ulaşılmıştır. Model 1'de piyasa yoğunlaşma ölçütü olarak belirlenen $\mathrm{CR}_{4}$ 'ün, ihracat yoğunluğu üzerindeki 
esneklik katsayısı 0.7 iken; diğer yoğunlaşma ölçütü olarak belirlenen HHI'nın ise esneklik katsayısı 0.4 olarak tespit edilmiştir.

İSO 1000 listesindeki imalat sanayi firmaları için ulaşılan ampirik bulgular, teorik çerçevede birbiri ile yarışan Porter'in rekabetçi hipotezine karşın, ulusal şampiyon yaklaşımını desteklemektedir. Çünkü rekabetçi yaklaşıma göre, piyasa yoğunlaşmasının artması, ihracatı negatif yönde etkilemektedir. Çalışmada ulaşılan bulgu, ampirik literatürde ulusal şampiyon yaklaşımını destekleyen, Cortes (2006), Güner vd. (2010) ile Reis ve Forte (2016) çalışmaları ile uyumludur. İSO listesi kapsamında, yoğunlaşmış endüstriler içerisindeki büyük firmalar, daha çok ve esnek girdi kullanarak, ihracata yönelmekte ve endüstri ihracatının artmasını sağlamaktadır. Yoğunlaşmış endüstriler içerisindeki büyük firmaların, küresel piyasalarda rekabet edebilecek gerekli kaynaklara sahip olması, ihracatın arttırılmasında önemli bir çıkarımdır. İhracatın artııılması hedefleyen sanayi politikalarının da bu çıkarım temel alınarak oluşturulması gerekmektedir.

İSO 1000 listesi, imalat sanayi için son derece önemli ve belirleyici konumda olmasına rağmen; imalat sanayinin genelini kapsamamakta ve piyasa yapısı özellikleri itibariyle imalat sanayinin genelinden ayrışabilmektedir. Bu nedenle bu çalışmanın, Türkiye ekonomisi imalat sanayinde piyasa yoğunlaşmasının dış ticarete etkisinin araştırılmasına yönelik bir ön-araştırma olarak değerlendirilmesi uygundur.

Çalışma kapsamında, piyasa yoğunlaşmasının haricinde endüstri ihracatçı oranı ve sermaye yoğunluğunun ihracat yoğunluğu üzerindeki etkisine yönelik önemli bulgulara ulaşılmıştır. Endüstrideki ihracatçı oranındaki artış, teorik beklentilere uygun şekilde ihracat yoğunluğunun artmasını sağlamaktadır. Aynı endüstride yer alan ihracatçı firmaların başarısı, diğer firmaların da ihracata yönelmesinde etkili olmaktadır. Sermaye yoğunluğunun ise ihracat yoğunluğu üzerinde etkisi bulunamamıştır.

En yüksek ciro değerine ulaşan ve ilk 1000 firma özelinde ulaşılan ampirik bulgular, İSO firmalarının dış ticaretteki ağırlığı ve başarısı düşünüldüğünde son derece önemlidir. Ancak, çalışma kapsamında elde edilen ampirik bulguların araştırılması ve dış ticaret ekseninde ayrıntılı politik önerilerde bulunulması için, daha çok firmayı kapsayan araştırmaların yapılması ihtiyaçtır. Piyasa yoğunlaşmasının ihracat üzerindeki etkisinin, dikkate alınmasında ölçek ekonomileri son derece önemlidir. Bu nedenle ölçek ekonomilerini de kapsayan ve gözlem sayısı fazla olan ampirik çalışma bulguları, Türkiye ekonomisi imalat sanayi için daha tutarlı sonuçların elde edilmesi için gerekmektedir. 
Ek. Tablo:1. Endüstri Tanımlamaları ve Firma Sayıs1

\begin{tabular}{|c|l|c|}
\hline Kod & Tanım & $\begin{array}{c}\text { Firma } \\
\text { Sayısı }\end{array}$ \\
\hline 10 & Gıda ürünlerinin imalatı & 64 \\
\hline 11 & İçeceklerin imalatı & 3 \\
\hline 12 & Tütün ürünleri imalatı & 1 \\
\hline 13 & Tekstil ürünlerinin imalatı & 49 \\
\hline 14 & Giyim eşyalarının imalatı & 10 \\
\hline 16 & Ağaç, ağaç ürünleri ve mantar ürünleri imalatı (mobilya hariç) & 2 \\
\hline 17 & Kağıt ve kağı ürünlerinin imalatı & 5 \\
\hline 18 & Kayıtlı medyanın basılması ve çoğaltılması & 1 \\
\hline 19 & Kok kömürü ve rafine edilmiş petrol ürünleri imalatı & 4 \\
\hline 20 & Kimyasalların ve kimyasal ürünlerin imalatı & 19 \\
\hline 21 & Temel eczacılık ürünlerinin ve eczacılığa ilişkin malzemelerin imalatı & 4 \\
\hline 22 & Kauçuk ve plastik ürünlerin imalatı & 10 \\
\hline 23 & Diğer metalik olmayan mineral ürünlerin imalatı & 28 \\
\hline 24 & Ana metal sanayii & 30 \\
\hline 25 & Fabrikasyon metal ürünleri imalatı (makine ve teçhizat hariç) & 10 \\
\hline 26 & Bilgisayarların, elektronik ve optik ürünlerin imalatı & 2 \\
\hline 27 & Elektrikli teçhizat imalatı & 9 \\
\hline 28 & Başka yerde sınıflandırılmamış makine ve ekipman imalatı & 10 \\
\hline & $\begin{array}{l}\text { Motorlu kara taşıtı, treyler (römork) ve yarı treyler (yarı römork) } \\
\text { imalatı }\end{array}$ & 27 \\
\hline 30 & Diğer ulaşım araçlarının imalatı & 3 \\
\hline 31 & Mobilya imalatı & 4 \\
\hline 32 & Diğer imalatlar & 3 \\
\hline 35 & Tıbbi ve dişçilik ile ilgili araç ve gereçlerin imalatı & 7 \\
\hline & & \\
\hline
\end{tabular}

\section{Kaynakça}

Bikker, J. A., \& Haaf, K. (2002). Measures of competition and concentration in the banking industry: a review of the literature. Economic \& Financial Modelling (Summer), 1-46.

Bramati, M. C., Gaggero, A. A., \& Solomon, E. (2015). International trade and domestic competition: evidence from Belgium. Review of Industrial Organization, 4(46), 383-399.

Clougherty, J. A., \& Zhang, A. (2009). Domestic rivalry and export performance: theory and evidence from international airline markets. Canadian Journal of Economics, 2(42), 440-468.

Cortes, B. S. (2006). Competition and export performance in Japan. The International Journal of Economic Policy Studies, 1(4), 71-82.

Coşkun, M. N., Ardor, H. N., Çermikli, A. H., Eruygur, H. O., Öztürk, F., Tokatlığlu, İ., Dağlaroğlu, T. (2012). Türkiye'de Bankacılık Sektörü Piyasa Yapısı, Firma Davranışları ve Rekabet Analizi. İstanbul: Türkiye Bankalar Birliği.

El-Osta, B., MacPhee, C. R., \& Rosenbaum, D. I. (19996). International trade, foreign direct investment, and domestic market performance. Eastern Economic Journal, 1(22), 63-73.

Fu, D., Wu, Y., \& Tang, Y. (2009). The effects of ownership structure and industry characteristics on export performance. The University of Western Australia.

Glejser, H., Jacquemin, A., \& Petit, J. (1980). Exports in an imperfect competition framework: an analysis of 1,446 exporters. The Quarterly Journal of Economics, 3(94), 507-524. 
Güner, B., Lee, J., \& Lucius, H. W. (2010). The impact of industry characteristics on export performance: a three country study. International Journal of Business and Economics Perspectives, 5(2), 126-141.

Henderson, D. R., \& Frank, S. D. (1990). Industrial organization and export competitiveness of u.s food manufacturers. 3rd Annual Symposium on International Economic Competitiveness.

Hollis, A. (2003). Industrial concentration, output and trade: an empirical exploration. Review of Industrial Organization, 2(22), 103-119.

Ildırar, M., \& Kıral, E. (2018). Piyasa yapısı ve yoğunlaşma: Türk otomotiv sektörü üzerine bir analiz. AİB̈̈ Sosyal Bilimler Enstitüsü Dergisi, 18(1), 93-117.

İSO (2021). Türkiye'nin 500 Büyük Sanayi Kuruluşu. Erişim tarihi: 01.02.2021, http://www.iso500.org.tr.

İSO (2020). Türkiye'nin 500 Büyük Sanayi Kuruluşu 2019. Erişim tarihi: 01.02.2021, https://www.iso500.org.tr/iso-500-dergileri/birinci-500-dergileri/

Jorde, T. M., \& Teece, D. J. (1990). Innovation and cooperation: implications for competition and antitrust. Journal of economic perspectives, 4(3), 75-96.

Kim, D., \& Marion, B. W. (1997). Domestic market structure and performance in global markets: theory and emprical evidence from U.S food manufacturing industries. Review of Industrial Organization, 12(3), 335-354.

Koo, A. Y., \& Martin, S. (1984). Market structure and U.S trade flows. International Journal of Industrial Organization 2, 173-197.

Lee, C. (2007). SCP, NEIO and Beyond (Working Paper Series b.). Selangor: Nottingham University Business School University of Nottingham Malaysia Campus.

Liu, X., \& Shu, H. (2003). Determinants of export performance: evidence from Chinese industries. Economics of Planning (36), 45-67.

O'Shaughnessy, E. (2018). Trends in the market structure of US residential solar PV installation, 2000 to 2016: An evolving industry. Prog Photovolt Res Appl (26), 901-910.

Pagoulatos, E., \& Sorensen, R. (1976). International trade, international investment and industrial profitability of U.S manufacturing. The Southern Economic Journal (42), 425-434.

Porter, M. E. (1990). The competitive advantage of nations. Harvard Business Review, 73-93.

Reis, J., \& Forte, R. (2016). The impact of industry characteristics on firms' export intensity. International Area Studies Review, 19 (3), 266-281.

Şahin, A. (2008). Dlş ticaret ve piyasa yoğunlaşması ilişkisi: Türk imalat sanayi üzerine bir uygulama. (Yayımlanmamış Yüksek Lisans Tezi). Yıldız Teknik Üniversitesi Sosyal Bilimler Enstitüsü, İstanbul.

TCMB (2021). Elektronik Veri Dağıtım Sistemi. Erişim tarihi: 01.02.2021, https://evds2.tcmb.gov.tr/.

TUiK. (2017). Sanayi ve Hizmet Sektörlerinde Yoğunlaşma. Erişim tarihi: 01.01.2021, https://data.tuik.gov.tr/Kategori/GetKategori?p=sanayi-114\&dil=1

TUiK (2021). Istatistik Veri Portal. Erişim tarihi: 01.02.2021, https://data.tuik.gov.tr/Kategori/GetKategori?p=dis-ticaret-104\&dil=1

U.S. Department of Justice and the Federal Trade Commission (2010). Horizontal merger guidelines. Erişim tarihi: 01.02.2021, https://www.justice.gov/atr/horizontal-merger-guidelines-08192010.

White, L. J. (1974). Industrial organization and international trade: some theoretical considerations. The American Economic Review, 64(6), 1013-1020.

Zhao, H., \& Zou, S. (2002). The impact of industry concentration and firm location on export propensity and intensity: an empirical analysis of Chinese manufacturing firms. Journal of International Marketing, 1(10), 52-71.

Zysman, J., \& Tyson, L. D. A. (1983). American industry in international competition: Government policies and corporate strategies. Cornell University Press. 